\title{
The effect of CIK-cell therapy in combination with anticancer agents in patients with inoperable pancreato- biliary cancer
}

\author{
Lee Jiyoung $^{1 *}$, Park Jinhee ${ }^{2}$, Chae Jinsung ${ }^{1}$, Jung Gyouchul ${ }^{3}$ and Yeom Changhwan ${ }^{1}$ \\ ${ }^{1}$ Department of Family Medicine, YCH Kospital, Republic of Korea \\ ${ }^{2}$ Department of Nutrition, YCH Hospital, Republic of Korea \\ ${ }^{3}$ Department of Family Medicine, GC I Med Clinic, Republic of Korea
}

\begin{abstract}
Objective: To examine the efficacy of a combination of anticancer agents and cytokine-induced killer (CIK) cell therapy in inoperable pancreato-biliary cancer patients.

Methods: We retrospectively reviewed the medical records of 17 inoperable pancreato-biliary cancer patients who were hospitalized from January 2015 to December 2019 in YCH hospital, Korea, and had received at least 5 treatments with CIK-cell therapy. The patients were all on chemotherapy. The major endpoints of the investigation were the overall survival time.

Results: A total of 17 patients were enrolled, $8(47.1 \%)$ males and $9(52.9 \%)$ females $(\mathrm{n}=17)$. The mean age was $61.7 \pm 7.8$ years. In types of cancer, the patients of pancreatic cancer were 6 , and biliary tract were 11 . At the survival time analysis, 8 patients (47.1\%) were still alive, but death occurred in 9 patients (52.9\%). The frequency of CIK-cell therapy was $8.2 \pm 4.1$. The overall median survival time was $553.0 \pm 129.9$ days (298.4 days - 807.6 days) (by Kaplan-Meier Method) which was 6-9 months longer than conventional treatment alone.
\end{abstract}

Conclusion: In this study CIK-cell therapy prolonged the survival of cancer patients without any major side effects when combined with anticancer drugs. A combination of Anticancer agents with cytokine-induced killer (CIK) cell can be a good proposal for improving the treatment outcomes for pancreatic and biliary cancer.

\section{Introduction}

Pancreatic and biliary (pancreato-biliary) cancers are common and the malignant tumor with poor prognosis. Likewise, the incidence of pancreato-biliary cancer has been gradually increased in Korea every year. From the statistics of Korea, the incidence was 5.05\% (pancreatic: $2.43 \%$, biliary: $2.62 \%$ ) in 2007 , while it showed $5.98 \%$ (pancreatic: $3.03 \%$, biliary: $2.95 \%$ ) in 2017 [1]. The only curative treatment for pancreatobiliary cancer is surgery. However, only fewer than $30 \%$ of these carcinomas are resectable due to the fact that the remaining majority of cases are diagnosed at inoperable advanced- or metastatic- stages [2]. The 5-year survival rate for these cancers (stage I-IV) was 12.2-28.9\%, and especially stage IV was $2.1-2.7 \%$ [1]. After tumor resection, many pancreato-biliary cancer patients experience recurrence of cancer. Neoadjuvant or adjuvant chemotherapy or/and radiation therapy do not seem to significantly lengthen the overall survival time. Hence, it is urgently required further studies to develop new drugs for more effective treatment of pancreato-biliary cancer.

Recently, immunotherapy has become an important part of cancer treatment, and immunotherapy with cytokine-induced killer (CIK) cells play an important role in tumor immune therapy [3]. CIK cells are lymphocytes stimulated with anti-CD3 monoclonal antibody, interleukin (IL)-2, IL-1, and interferon gamma (IFN-r), and the cytotoxic activity of CIK cells are not restricted by major histocompatibility complex (MHC) on target cells [4]. In patients who underwent curative treatment for HCC (hepatocellular carcinoma), adjuvant immunotherapy with activated CIK cells increased recurrencefree and overall survival [5]. CIK cell therapy has been used in advanced lung cancer as an alternative therapeutic strategy to improve disease control rates, either alone or in combination with chemotherapy.[6] In this study, we aimed to assess the efficacy and safety of the CIK-cell therapy as an adjuvant therapy for pancreato-biliary cancer.

\section{Method}

\section{Patients}

We retrospectively reviewed the medical records of inoperable advanced pancreato-biliary cancer patients who were hospitalized from January 2015 to December 2019 in YCH hospital, Korea, and had received at least 5 treatments with CIK-cell therapy. The patients were all on chemotherapy.

${ }^{*}$ Correspondence to: Jiyoung,Lee, Department of Family Medicine, YCH Kospital, Seoul 06605, Republic of Korea, E-mail: hello.muzzica@gmail.com

Key words: immunotherapy, pancreato-biliary cancer, pancreatic cancer, biliary tract cancer, cytokine-induced killer cell (CIK)

Received: April 09, 2020; Accepted: April 25, 2020; Published: April 28, 2020 


\section{Assessment of cancer patients}

The demographic data of the patients were examined including gender, age, cancer type, recurrence, and metastasis. We evaluated adverse effects including fever, allergy, hypotension, edema, and the other side effects before/after CIK-cell therapy administration. To assess the allergic reaction, we performed skin prick test before CIKcell therapy administration. In skin prick test, we injected $1 \mathrm{cc}$ of cultured cells into the patient's epidermis and confirmed the reaction after 15 minutes. We evaluated as positive when the size of the wheal and the flare was $>3 \mathrm{~mm}$ and $>10 \mathrm{~mm}$, respectively. Overall survival was defined as the time from the first diagnosis to death.

\section{Statistical analysis}

Demographic data and side effects of CIK-cell therapy were evaluated for frequency. Also, the mean survival time after CIK-cell therapy administration was analyzed using the Kaplan-Meier method. All analyses were conducted using the SPSS statistical software package version 26.0 (SPSS, Inc., Chicago, Il, USA).

\section{Results}

A total of 17 patients were enrolled, 8 (47.1\%) males and $9(52.9 \%)$ females $(n=17)$. The mean age was $61.7 \pm 7.8$ years. In types of cancer, the patients of pancreatic cancer were 6 , and biliary tract were 11 . At the survival time analysis, 8 patients $(47.1 \%)$ were still alive, but death occurred in 9 patients (52.9\%). The frequency of CIK-cell therapy was $8.2 \pm 4.1$ (Table 1 ).

In the skin prick test before CIK-cell therapy, only one patient showed skin prick test positive (5.9\%) (Table 2). This lesion was more than $1 \mathrm{~cm}$ in diameter. To prevent this allergic reaction, the patient was administrated with a premedication, $2 \mathrm{mg}$ peniramine as an antihistamine agent, before CIK-cell therapy administration. As a result, the skin wheal and flare didn't arise from the patient. The side effects caused by CIK-cell therapy were as follows. After administration of CIK cells to the patients, fever was observed in 3 patients (17.6\%), and they showed $37.7,38$, and $38.1{ }^{\circ} \mathrm{C}$, respectively. Aside from above findings, we could not observe any other adverse events, including hypotension and edema, during and after treatment (Table 3 ).

The overall median survival time was $553.0 \pm 129.9$ days $(298.4$ days - 807.6 days) (by Kaplan-Meier Method) (Figure 1).

\section{Discussion}

Pancreatic and biliary tract cancers have very poor prognosis and response to chemotherapy. As a result, the survival period is not long.

Table 1. Demographic data

\begin{tabular}{|l|c|c|}
\hline \multicolumn{2}{|c|}{} & Numerical / Percent Value \\
\hline \multirow{2}{*}{ Gender } & male & $8(47.1 \%)$ \\
\hline Ages & female & $9(52.9 \%)$ \\
\hline Cancer & & $61.7 \pm 7.8$ \\
\hline Type & pancreas & $6(35.3 \%)$ \\
\hline \multirow{2}{*}{ Stage } & biliary & $11(64.7 \%)$ \\
\hline Recurrence & III & $5(41.7 \%)$ \\
\hline Death & IV & $12(58.3 \%)$ \\
\hline Chemotherapy & & $6(35.3 \%)$ \\
\hline CIK-cell therapy & & $9(52.9 \%)$ \\
\hline Total Patients & & $17(100.0 \%)$ \\
\hline
\end{tabular}

Table 2. Side effects of CIK-cell therapy

\begin{tabular}{|c|c|}
\hline Side effects & Number of patients (\%) \\
\hline Fever & $3 / 17(17.6 \%)$ \\
\hline Allergy & $1 / 17(5.9)$ \\
\hline Hypotension & $0 / 17(0.0 \%)$ \\
\hline Edema & $0 / 17(0.0 \%)$ \\
\hline The Others & $0 / 17(0.0 \%)$ \\
\hline
\end{tabular}

Table 3. Overall survival time (median $\pm \mathrm{SD}$ )

\begin{tabular}{|c|c|}
\hline & Median time \pm SD (low - high) \\
\hline overall survival time (days) & $553.0 \pm 129.9(298.4-807.6)$ \\
\hline
\end{tabular}

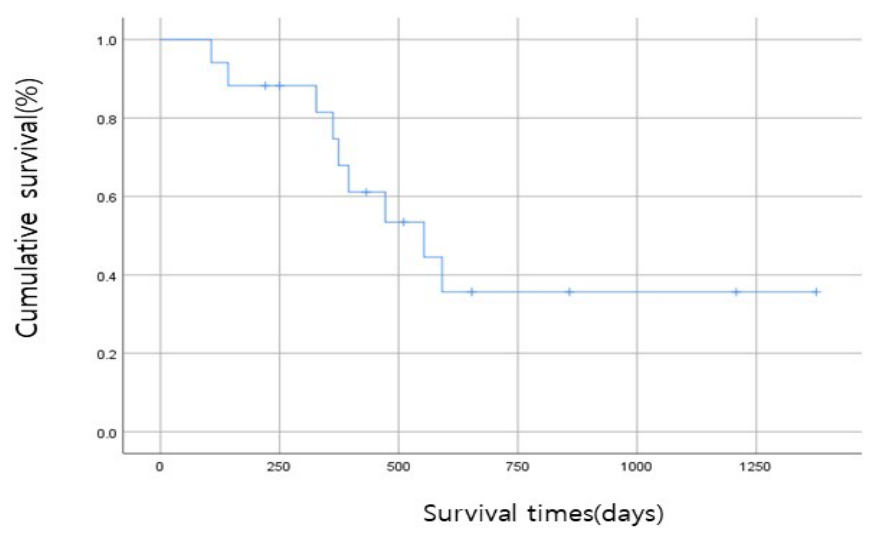

Figure 1. Overall survival (OS) after CIK-cell therapy with chemotherapy. The median OS was 553.0 days ( $95 \%$ confidence interval, 298.4 - 807.6 days)

For this reason, new treatments have been proposed, but they have not achieved remarkable outcomes.

This study was performed to evaluate the effectiveness of CIKcell treatment in combination with anticancer drugs in patients with inoperable pancreatic and biliary tract cancer. The overall survival time was $553.0 \pm 129.9$ days (298.4 days-807.6 days) (Table 3 ). In the chemotherapy of pancreatic cancer alone, the median survival time is about 9 months for unresectable locally advanced disease, and the median survival value for metastatic disease is about 6 months. In the chemotherapy of bile duct cancer alone, the median survival time was 8.1-11.7 months. In contrast, the median survival time of combination therapy with anticancer drugs and CIK-cell therapy was 18.4 months. Consequently, these data show that the combination of CIK-cell treatment and chemotherapy extended the survival time by 6-9 months compared to the conventional treatment [2].

Immunotherapy were lymphokine-activated killer (LAK) cells, CIK (cytokine-induced killer) cells, and NK cells, all of which can mediate cancer regression with non MHC restriction. NK cells, phenotypically defined as CD3-CD56+ lymphocytes, can rapidly lyse certain target cells without MHC restriction [7]. By cytokine stimulation, autologous NK cells can be transformed into LAK cells and exhibit greater cytotoxicity against tumor cells. In 1985, Rosenberg et al, introduced the LAK cells to the treatment for cancer [8]. However, the clinical response rate of LAK cell was not good [9].

CIK cells have enhanced cytotoxic activity compared to LAK cells. CIK cells are lymphocytes stimulated with anti-CD3 monoclonal antibody, interleukin (IL)-2, IL-1, and interferon gamma (IFN-r) [10]. The cytotoxic activity of CIK cells are not restricted by major histocompatibility complex (MHC) on target cells. Both in vitro and in vivo studies have indicated that CIK cells exhibit high cytotoxicity on 
tumor cells [4] According to scientific findings, CIK cells express CD4 and CD8 markers, and most of them express surface CD3 and CD56 molecules as well. In addition, CIK cells can kill multi-drug resistance cells [11]. Therefore, the combination of chemotherapy and CIK cell therapy may have a synergistic effect.

In our studies, fever accounted for the highest frequency of the side effects shown after CIK-cell therapy (17.4\%), however, it went down in a short time after being orally treated with $500 \mathrm{mg}$ of acetaminophen. Allergic reaction was not frequent adverse by CIK-cell therapy, but one patient showed a positive response for the skin prick test before the therapy (5.9\%). Besides, we could not find any skin problems after using an antihistamine (peniramin) to the patient prior to administrate CIK cells. These results support that CIK-cell therapy has no fatal side effects enough to stop the treatment. During the past decades, CIK cell therapy has been confirmed to be effective and safe in several types of cancers without notable toxic and / or adverse events [12-15].

To date, a number of clinical trials have been conducted to evaluate the efficacy of CIK cells in treating various types of cancer patients. According to a phase III randomized controlled trial (RCT), CIK cells were reported to strengthen the immune system and reduce recurrence in patients with hepatocellular carcinoma. Accordingly, in patients who received curative treatment for HCC, the significant improvement in RFS and OS as a result of adjuvant CIK cell immunotherapy lasted over 5 years without boosting [16].

In Jiang's report, the survival time of the gastric cancer patients treated with chemotherapy combined with CIK cell therapy is significantly longer than that of the patients treated with chemotherapy alone. Also, increasing the frequency of CIK cell therapy decreased risk of death [17].

In conclusion, as mentioned above, pancreatic and biliary tract cancers are notorious for not only responding poorly to chemotherapy but also having a short survival period. In this study, we showed that CIK-cell therapy prolonged the survival of cancer patients without any major side effects when combined with anticancer drugs. From this point of view, this retrospective study can be a good proposal for improving the treatment outcomes for pancreatic and biliary cancer.

\section{Reference}

1. Korean National Registration Statistics. 2017. [https://www.ncc.re.kr/cancerStatsList. ncc? searchKey $=$ total\&search Value $=$ \&pageNum $=1]$
2. Harrison Yang L, Ren B, Li H, Yu J, Cao S, et al. (2013) Enhanced antitumor effects of DC-activated CIKs to chemotherapy treatment in a single cohort of advanced nonsmall-cell lung cancer patients. Cancer Immunol Immunother 62: 65-73. [Crossref]

3. Qian X, Wang X, Jin H (2014) Cell Transfer Therapy for Cancer: Past, Present, and Future. J Immunol Res. 2014; 2014: 525913. [Crossref]

4. Lee JH, Lee JH, Lim YS, Yeon JE, Song TJ, et al. (2015) Adjuvant Immunotherapy with Autologous Cytokine-Induced Killer Cells for Hepatocellular Carcinoma. Gastroenterology 148: 1383-1391. [Crossref]

5. Wu C, Jiang J, Shi L, Xu N (2008) Prospective study of chemotherapy in combination with cytokine-induced killer cells in patients suffering from advanced non-small cell lung cancer. Anticancer Res 28: 3997-4002. [Crossref]

6. Cheng M, Chen Y, Xiao W, Sun R, Tian Z (2013) NK cell-based immunotherapy for malignant diseases. Cell Mol Immunol 10: 230-252. [Crossref]

7. Rayner AA, Grimm EA, Lotze MT, Chu EW, Rosenberg SA (1985) Lymphokineactivated killer (LAK) cells. Analysis of factors relevant to the immunotherapy of human cancer. Cancer 55: 1327-1333. [Crossref]

8. Law TM, Motzer RJ, Mazumdar M, Sell KW, Walther PJ, et al. (1995) Phase III randomized trial of interleukin-2 with or without lymphokine activated killer cells in the treatment of patients with advanced renal cell carcinoma. Cancer 76: 824-832. [Crossref]

9. Jiang J, Wu C, Lu B (2013) Cytokine-induced killer cells promote antitumor immunity. J Transl Med 2013; 11: 83. [Crossref]

10. Schmidt-Wolf IG, Lefterova P, Johnston V, Scheffold C, Csipai M, et al. (1996) Sensitivity of multidrug-resistant tumor cell lines to immunologic effector cells. Cell Immunol 169: 85-90. [Crossref]

11. Chung MJ, Park JY, Bang S, Park SW, Song SY (2014) Phase II clinical trial of ex vivo-expanded cytokine-induced killer cells therapy in advanced pancreatic cancer. Cancer Immunol Immunother 63: 939-946. [Crossref]

12. Liu L, Zhang W, Qi X, Li H, Yu J, et al. (2012) Randomized study of autologous cytokine-induced killer cell immunotherapy in metastatic renal carcinoma. Clin Cancer Res 18: 1751-1759. [Crossref]

13. Zhu X, Xu Y, Zhou J, Pan X (2014) A clinical study evaluating dendritic and cytokineinduced killer cells combined with concurrent radiochemotherapy for stage IIIB nonsmall cell lung cancer. Genet Mol Res 14: 10228-10235. [Crossref]

14. Pan K, Guan XX, Li YQ, Zhao JJ, Li JJ, et al. (2014) Clinical activity of adjuvan cytokine-induced killer cell immunotherapy in patients with post-mastectomy triplenegative breast cancer. Clin Cancer Res 20: 3003-3011. [Crossref]

15. Lee JH, Lee JH, Lim YS, Yeon JE, Song TJ, et al. (2019) Sustained efficacy of adjuvant immunotherapy with cytokine-induced killer cells for hepatocellular carcinoma: an extended 5-year follow-up. Cancer Immunol Immunother 68: 23-32. [Crossref]

16. Jiang JT, Shen YP, Wu CP, Wei WX, Chen LJ, et al. (2010) Increasing the frequency of CIK cells adoptive immunotherapy may decrease risk of death in gastric cancer patients. World J Gastroenterol 16: 6155-6162. [Crossref]

Copyright: (C2020 Jiyoung L. This is an open-access article distributed under the terms of the Creative Commons Attribution License, which permits unrestricted use, distribution, and reproduction in any medium, provided the original author and source are credited. 